Check for updates

Cite this: Chem. Commun., 2019, 55, 1156

Received 27th November 2018, Accepted 19th December 2018

DOI: $10.1039 / c 8 c c 09437 c$

rsc.li/chemcomm

\section{Enzyme-assisted self-assembly within a hydrogel induced by peptide diffusion $\dagger$}

\author{
Miryam Criado-Gonzalez, (D) abc Jennifer Rodon Fores, ${ }^{a}$ Déborah Wagner, ${ }^{a}$ \\ André Pierre Schröder, ${ }^{a}$ Alain Carvalho, ${ }^{a}$ Marc Schmutz, (D) a Eva Harth, (D) d \\ Pierre Schaaf, ${ }^{* a b c}$ Loïc Jierry (D) ${ }^{a}$ and Fouzia Boulmedais (D) *a
}

The diffusion of adequate peptide through an enzyme-embedded host hydrogel leads to the in situ start-up and growth of an interpenetrated fibrous network. Based on the enzyme-assisted self-assembly concept, both chemistry and mechanical features of the hybrid hydrogel can be tuned.

Hydrogels have been used for decades as substrates for cell growth and tissue engineering. ${ }^{1}$ Historically, they are based on cross-linked polymer networks and referred to as chemical gels or on polymer chains interacting through ionic or hydrogen bonds. The latter are referred to as physical gels. More recently, hydrogels were developed based on low molecular weight hydrogelators (LMWHs) capable of self-assembling into entangled fibrils through $\mathrm{H}$ bonding, van der Waals forces, $\pi-\pi$ interactions or metal-ligand bonds. ${ }^{2}$ Over the last few years, it has become increasingly apparent that fine tuning of the mechanical and chemical properties of the substrate is of paramount importance in guiding cell fate. ${ }^{3}$ In addition, tissues are also highly structured, presenting morphological, biochemical and mechanical gradients. ${ }^{4}$ Thus, these features have led to the development of new types of hydrogels trying to mimic some of these properties. Among them, double networks using LMWHs are of great interest. ${ }^{5}$ Generally this kind of hydrogel is composed of a polymer network interpenetrated with a supramolecular one both formed simultaneously in the bulk. ${ }^{6}$ Such double networks can present mechanical properties that can closely match those of living tissues such as cartilage. ${ }^{7}$ Of particular interest is their

\footnotetext{
${ }^{a}$ Université de Strasbourg, CNRS, Institut Charles Sadron UPR 22, 67034 Strasbourg, France. E-mail: schaaf@unistra.fr, Loic.Jierry@ics-cnrs.unistra.fr, fouzia.boulmedais@ics-cnrs.unistra.fr

${ }^{b}$ Institut National de la Santé et de la Recherche Médicale, UMR-S 1121, "Biomatériaux et Bioingénierie", 67087 Strasbourg, France

${ }^{c}$ Université de Strasbourg, Faculté de Chirurgie Dentaire, Fédération de Médecine Translationnelle de Strasbourg and Fédération des Matériaux et Nanoscience d'Alsace, 67000 Strasbourg, France

${ }^{d}$ Department of Chemistry, Center of Excellence in Polymer Chemistry, University of Houston, Houston, Texas 77030, USA

† Electronic supplementary information (ESI) available. See DOI: 10.1039/ c8cc09437c
}

enhanced mechanical damage resistance due to the energy dissipation under stress related to the weakness of the intermolecular bonds and their reversible character. The self-assembled network of amino acids in a physical gel also allows control of the release of small molecules. ${ }^{7}$ The next goal to achieve in this field is to design biomaterials in which the interpenetrated network could be started-up and grown when desired at specific and precise spatial locations in the host hydrogel (local or gradual positions), and with a fine control of the self-assembly evolution over time (growth, disassembly, periodicity). Indeed the control of spatiotemporal interaction between molecular entities in complex chemical environments is a sine qua non challenge to overpass toward the design of artificial biological tissues or organs. ${ }^{8}$ One emerging way to this end is the use of reaction-diffusion processes in organic materials. ${ }^{9}$ Up to now, only a few examples have highlighted the strength of the diffusion-reaction approach for spatial organization..$^{10}$ In particular, Eelkema, van Esch and coworkers have shown the possibility of the diffusion of hydrogelator precursors within a host material from defined positions. ${ }^{11}$ Thanks to proton catalysis, precursors transform into hydrogelators that self-assemble, leading to macroscale objects with a control of their shape, size and chemical functionalities.

Herein, we demonstrated the possibility of using the diffusion of non-self-assembling compounds into an enzyme-embedded material to initiate the growth of a nanofibrous network specifically within the host material, thus changing both its chemical composition and mechanical properties. The enzyme located inside the host hydrogel spontaneously transforms the diffusing compound into a self-assembling building block, an approach called enzyme-assisted self-assembly (EASA), pioneered by Xu in $2004^{12}$ and extended by Ulijn ${ }^{13}$ and others. ${ }^{14}$ More specifically, thanks to the diffusion of the tripeptide Fmoc-FF $p$ Y (Scheme 1a) into a poly(ethylene glycol) (PEG) hydrogel containing alkalinephosphatase (AP), Fmoc-FFY is generated in situ through enzymatic dephosphorylation, which then self-assembles. Indeed, AP has been shown to transform Fmoc-FF $p$ Y into Fmoc-FFY efficiently, which self-assembles through $\pi-\pi$ stacking between the aromatic rings and H-bonding. ${ }^{14 b}$ 
a.

b.
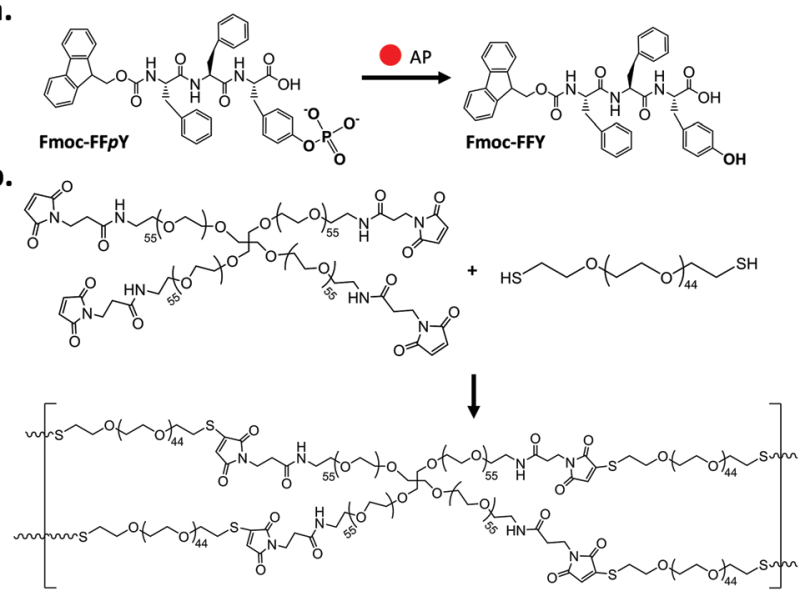

c.

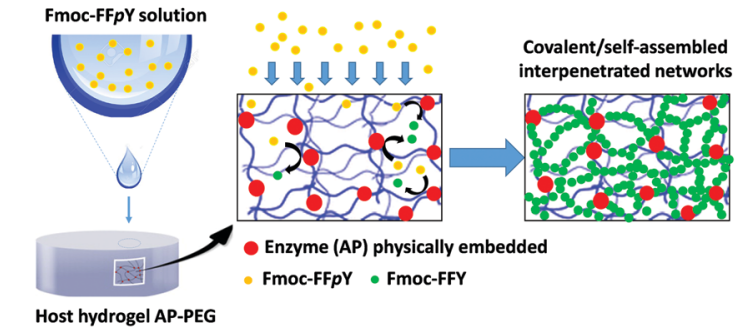

Scheme 1 (a) Fmoc-FFpY dephosphorylation by AP yielding Fmoc-FFY; (b) covalent network of the PEG hydrogel through the thiol-ene click reaction between HS-PEG44-SH and 4-arm-PEG55 maleimide; (c) schematic representation of the hybrid covalent/self-assembled network designed through peptide diffusion within the AP-embedded host hydrogel.

The covalent PEG hydrogel was prepared through thiol-ene click chemistry by mixing a homobifunctional PEG thiol $\left(M_{\mathrm{w}}=2 \mathrm{kDa}\right)$ and a 4-arm-PEG maleimide $\left(M_{\mathrm{w}}=10 \mathrm{kDa}\right)$ in water (Scheme 1b). ${ }^{15}$ An enzymatically active PEG gel, named AP-PEG, was obtained by physically trapping AP during PEG gel formation. Drops of Fmoc-FFpY solution can be deposited onto the surface of the enzymatically active covalent hydrogel AP-PEG. The diffusion of this solution occurs in a few minutes into the host gel (Scheme 1c).

First of all, AP was mixed in the PEG precursor solution before the covalent hydrogelation process (see the Material and methods section in the ESI $\dagger$ ). Once the AP-PEG gel was obtained, we checked that the enzymatic activity of AP was maintained. para-Nitrophenyl phosphate (PNP) was used as the model substrate and a few drops of it were added on the AP-PEG gel. Thus, the enzymatic phosphate hydrolysis of PNP leading to the release of para-nitrophenol was monitored easily by UV spectrophotometry (Fig. S1 in the $\mathrm{ESI} \dagger$ ). One observes that AP remains active within the PEG gel. $25 \mu \mathrm{L}$ of Fmoc-FFpY solution $\left(2.5 \mathrm{mg} \mathrm{mL}^{-1}\right)$ was then deposited on the top of the AP-PEG gel. The diffusion of Fmoc-FF $p$ Y within the enzymatically active host PEG gel takes place in a few minutes. The integrity of the host gel is maintained even after 24 hours, and its transparency as well, without a noticeable swelling effect (Fig. S2 in the ESI $\dagger$ ).

The in situ formation of Fmoc-FFY and its resulting self-assembly were first evidenced by Fourier transformed infrared (FTIR)

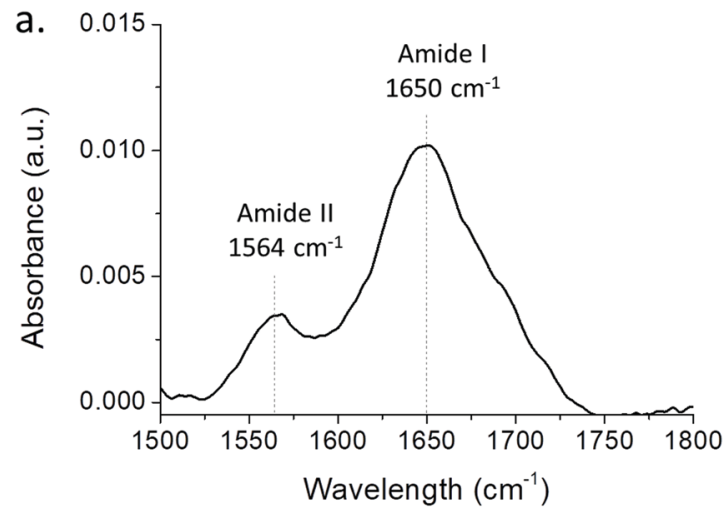

b.

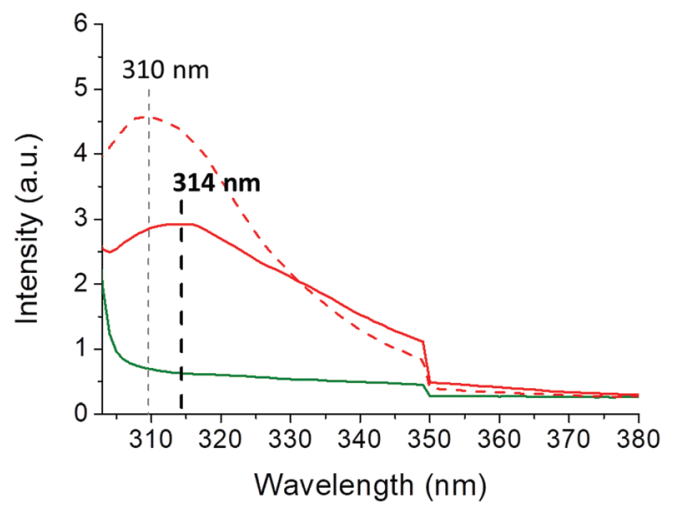

Fig. 1 (a) FTIR spectrum of the AP-PEG hydrogel $24 \mathrm{~h}$ after the diffusion of Fmoc-FFpY (2.5 mg mL $\mathrm{mL}^{-1}$ ) and (b) fluorescence emission spectra $\left(\lambda_{\mathrm{ex}}=290 \mathrm{~nm}\right)$ of the AP-PEG gel (solid green line), $1 \mathrm{~h}$ (dashed red line) and $24 \mathrm{~h}$ (solid red line) after the Fmoc-FFpY diffusion.

spectroscopy in the attenuated total reflection mode in deuterated water. FTIR spectra of the AP-PEG gel were recorded before and $24 \mathrm{~h}$ after the deposition of the Fmoc-FFpY solution. One observes a band at $1650 \mathrm{~cm}^{-1}$ assigned to the carbonyl groups of the amide involved in the antiparallel $\beta$-sheet assemblies (Fig. 1a). ${ }^{14 b, 16}$ Fluorescence emission spectroscopy was also performed to confirm the presence of the Fmoc excimer signature as usually observed in peptide-based self-assemblies generated in water. ${ }^{14 b, 17}$ The Fmoc-FF $p$ Y solution exhibits a fluorescence emission at $310 \mathrm{~nm}$ when excited at $290 \mathrm{~nm}$ due to the presence of the Fmoc group. In the presence of AP, Fmoc-FFY self-assembly occurs and a shift of the fluorescence emission towards $314 \mathrm{~nm}$ is observed due to the Fmoc excimer formation (Fig. S3 in the $\mathrm{ESI} \dagger)$. When $25 \mu \mathrm{L}$ of Fmoc-FFpY solution $\left(2.5 \mathrm{mg} \mathrm{mL}^{-1}\right)$ is deposited onto the AP-PEG gel, a shift of the fluorescence emission from $310 \mathrm{~nm}$ at $t=0$ up to $314 \mathrm{~nm}$ at $t=24 \mathrm{~h}$ is measured (Fig. 1b), similar to that observed in solution. No shifts were observed for Fmoc-FFpY diffusing within the PEG gel embedding no AP or when Fmoc-G, a non-self-assembling amino acid (G: glycine), was deposited onto the AP-PEG hydrogel (Fig. S3 in the ESI $\dagger$ ). These control experiments show the physical presence of Fmoc-FFY self-assembly inside the host material and its specific generation in the presence of AP.

The formation of the supramolecular self-assembly of FmocFFY within the AP-PEG gel was visualized by confocal laser 

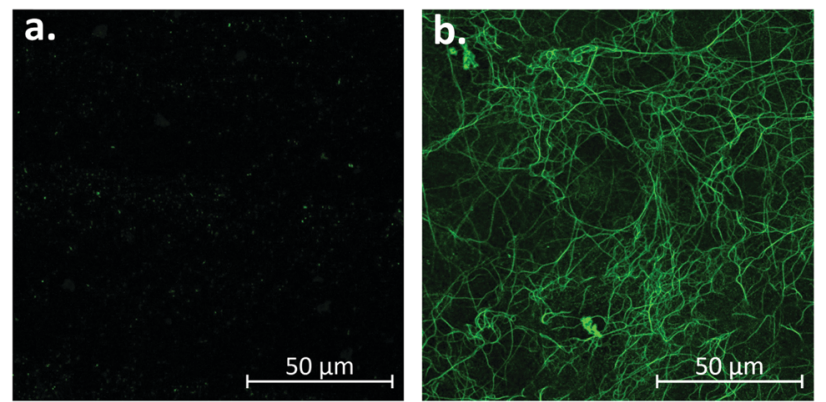

Fig. 2 Confocal images of the AP-PEG gel containing ThT (a) before and (b) $24 \mathrm{~h}$ after the diffusion of $25 \mu \mathrm{L}$ of Fmoc-FFpY $\left(2.5 \mathrm{mg} \mathrm{mL}^{-1}\right)$. The absence of fluorescence emission originating from ThT oligomerization is confirmed by (a).

scanning microscopy using Thioflavin $\mathrm{T}$ (ThT), a dye that reveals $\beta$-sheet secondary structures through a green emission of fluorescence intensity. First of all, it must be noted that the presence of ThT in the AP-PEG gel does not lead to fluorescence emission, thus excluding the potential artefact coming from the oligomerization of ThT (Fig. 2a). The diffusion of FmocFF $p$ Y within the AP-PEG gel (containing ThT) results in a full green fluorescence emission in the whole material that did not allow observation of any structuration. This might be due to a highly dense stacking of the $\beta$-sheet moieties. However, the use of a lower concentration of ThT allows the observation of the formation of the network composed of several hundred micrometres long fibres (Fig. 2b and Fig. S4 in the ESI $\dagger$ ). This entanglement of fibres having a homogeneous fluorescent fibrillary structure in the presence of ThT has spread throughout the gel according to the images taken at several micrometers depth (Fig. S5, ESI $\dagger$ ). It must be noted that no fibrous network was observed at all in the absence of AP embedded in the host PEG gel (Fig. 2a) or when Fmoc-G diffused within the AP-PEG gel instead of Fmoc-FF $p$ Y (Fig. S8 in the ESI $\dagger$ ). Because of the absorbance of AP-PEG in the spectral region from 190 to $240 \mathrm{~nm}$, circular dichroism monitoring of the self-assembly process was not an adapted analytical method.

The morphology of the internal architecture of the hybrid covalent/self-assembled network was visualized by cryo scanning electron microscopy (Cryo-SEM). $24 \mathrm{~h}$ after the diffusion of Fmoc-FF $p$ Y within the AP-PEG gel, a highly dense fibrous network was observed (Fig. 3), similar to the one observed when AP and Fmoc-FFpY were mixed (Fig. S7 in the ESI $\dagger$ ). Two levels of organization appear with micrometer fibers highly
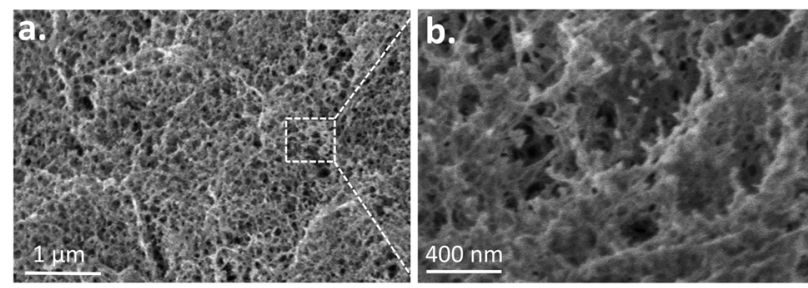

Fig. 3 (a) Cryo-SEM images and (b) magnification of the AP-PEG hydrogel $24 \mathrm{~h}$ after the diffusion of $25 \mu \mathrm{L}$ of Fmoc-FFpY $\left(2.5 \mathrm{mg} \mathrm{mL}^{-1}\right)$. stacked together but also with isolated nanofibers showing diameters less than $100 \mathrm{~nm}$. In contrast, it was not possible to image AP-PEG by cryo-SEM due to the difficulty in obtaining good freezing conditions, avoiding water crystallization. This could be explained by the weak crosslinking density of the organic matter in the AP-PEG gel. Thus, both fluorescence and cryo-SEM investigations have confirmed that the growth of nano and microstructures can be initiated and then grown within a host hydrogel using the enzyme-assisted self-assembly approach. As far as we know, the use of this strategy has never been reported.

Because the diffusion of a peptide inside the AP-PEG hydrogel can trigger a change in both the chemical composition and the internal morphology of the host gel, we can expect that its mechanical properties will also be affected. This was determined through dynamic oscillatory rheology as a function of frequency and strain providing information of the storage $\left(G^{\prime}\right)$ and the loss moduli $\left(G^{\prime \prime}\right) . G^{\prime}$ is employed as an indicator of the elastic behaviour of the material by measuring the ability to store deformation energy, which can be recovered after removing the applied load. $G^{\prime \prime}$ measures the deformation energy that is dissipated as heat and friction during the shearing process. ${ }^{18}$ The AP-PEG gel shows a little frequency dependence at $0.06 \%$ strain up to $1 \mathrm{~Hz}$. At a frequency of $1 \mathrm{~Hz}, G^{\prime}$ (resp. $G^{\prime \prime}$ ) takes a value of $317 \pm 15 \mathrm{~Pa}$ (resp. $15 \pm 0.1 \mathrm{~Pa}$ ). 24 hours after the diffusion of $25 \mu \mathrm{L}$ of Fmoc-FFpY solution $\left(2.5 \mathrm{mg} \mathrm{mL}^{-1}\right)$ within the AP-PEG hydrogel, the $G^{\prime}$ value (resp. $G^{\prime \prime}$ ) reaches $436 \pm 35 \mathrm{~Pa}$ (resp. $33 \pm 6 \mathrm{~Pa}$ ) (Fig. 4 and Fig. S8, Table S1 in the ESI $\dagger$ ). When a lower concentration of Fmoc-FFpY $\left(1 \mathrm{mg} \mathrm{mL}^{-1}\right)$ or a solution of a non-self-assembling compound such as Fmoc-G $\left(2.5 \mathrm{mg} \mathrm{mL}^{-1}\right)$ was used, almost no variation of both $G^{\prime}$ and $G^{\prime \prime}$ was observed. The generation of the self-assembled system within the host material increases the global network density, thus explaining the increase of the storage modulus after the diffusion of FmocFFpY within the AP-PEG hydrogel. In addition, the doubling of the $G^{\prime \prime}$ value compared to that of the AP-PEG hydrogel must be related to the ability of the peptide self-assembled network to dissipate energy under stress due to its non-covalent character (Fig. 4 and Fig. S9 in the ESI $\dagger$ ).

In conclusion, we have shown that a tripeptide generated in situ within an enzymatically active chemical hydrogel can
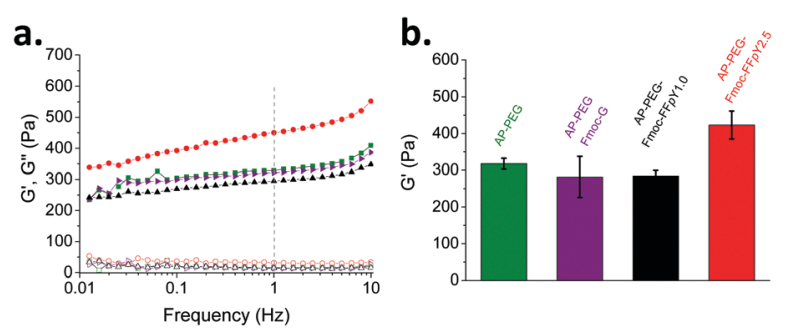

Fig. 4 (a) Storage modulus ( $G^{\prime}$ - solid symbols) and loss modulus ( $G^{\prime \prime}$ - hollow symbols) as a function of the frequency of the AP-PEG gel $(\square)$ before and after contact with (A) $1 \mathrm{mg} \mathrm{mL}^{-1}$ Fmoc-FFpY, (O) $2.5 \mathrm{mg} \mathrm{mL}^{-1} \mathrm{Fmoc}-$ FFpY or $\left(\right.$ ) $2.5 \mathrm{mg} \mathrm{mL}^{-1}$ of Fmoc-G solutions for $24 \mathrm{~h}$. (b) Storage modulus $\left(G^{\prime}\right)$ at $1 \mathrm{~Hz}$ for the four samples studied. The results are shown as mean $\pm \mathrm{sd}(n=3)$. 
self-assemble, giving rise to the formation of a supramolecular network inside the covalent host material. This interpenetrated network results from the local start-up and growth of the tripeptidebased nano and microfibers that change both the chemical constitution and the internal morphology of the material and also enhances the mechanical properties through the increase of the storage and loss moduli as well. The originality of this work relies on the possibility of initiating the formation of a secondary selfassembled network through an enzymatic trigger embedded within a material, an approach never reported so far. The control of the enzyme localization into a host 3D environment opens the gate to the spatial tuning of both the chemistry and the mechanical properties of the considered material. We believe that the locally controlled diffusion of chemicals leading to spatially defined architectures represents a powerful tool for complex chemical system development, the design of artificial cells or living tissues and thus can find applications in the field of tissue engineering and in mechanotransduction investigations.

M. C.-G. acknowledges the IDEX of the Universite de Strasbourg for granting a post-doctoral fellowship. J. R. F. and D. W. acknowledge the International Center for Frontier Research in Chemistry (Labex CSC, PSC-016 and PSC-005) for PhD and Master funding, respectively. E. H. is grateful to the Région Alsace, Département du Bas-Rhin and the Communauté Urbaine de Strasbourg for the award of a Gutenberg Excellence Chair. The ICS microscopy platform is acknowledged for the use of the SEM instrument. We gratefully acknowledge the financial support from the Agence Nationale de la Recherche (EASA, ANR-18-CE06-0025-03) and the Institut Carnot-MICA.

\section{Conflicts of interest}

There are no conflicts to declare.

\section{Notes and references}

1 Biomedical Applications of Hydrogels Handbook, ed. R. M. Ottenbrite, K. Park and T. Okano, Springer, 2010.

2 N. M. Sangeetha and U. Maitra, Chem. Soc. Rev., 2005, 34, 821-836.

3 J. H. Wen, L. G. Vincent, A. Fuhrmann, Y. S. Choi, K. C. Hribar, H. TaylorWeiner, S. Chen and A. J. Engler, Nat. Mater., 2014, 13, 979-987.
4 A. Seidi, M. Ramalingam, I. Elloumi-Hannachi, S. Ostrovidov and A. Khademhosseini, Acta Biomater., 2011, 4, 1441-1451.

5 E. R. Draper, E. G. B. Eden, T. O. McDonald and D. J. Adams, Nat. Chem., 2015, 7, 848-852; J. Wang, Z. Wang, J. Gao, L. Wang, Z. Yang, D. Kong and Z. Yang, J. Mater. Chem., 2009, 19, 7892-7896; J. Wang, X. Miao, Q. Fengzhao, C. Ren, Z. Yang and L. Wang, RSC Adv., 2013, 3, 16739-16746.

6 D. J. Cornwell and D. K. Smith, Mater. Horiz., 2015, 2, 279-293.

7 W. X. Sun, B. Xue, Y. Li, M. Qin, J. Y. Wu, K. Lu, J. H. Wu, Y. Cao, Q. Jiang and W. Wang, Adv. Funct. Mater., 2016, 26, 9044-9052.

8 K. Powell, Nature, 2018, 563, 172-175.

9 S. Kondo and T. Miura, Science, 2010, 329, 1616-1620; S. Soh, M. Byrska, K. Kandere-Grzybowska and B. Grzybowski, Angew. Chem., Int. Ed., 2010, 49, 4170-4198.

10 I. Ziemecka, G. J. M. Koper, A. G. L. Olive and J. H. van Esch, Soft Matter, 2013, 9, 1556-1561; T. S. Shim, S. M. Yang and S. H. Kim, Nat. Commun., 2015, 6, 6584.

11 M. Lovrak, W. E. J. Hendriksen, C. Maity, S. Mytnyk, V. van Steijn, R. Eelkema and J. H. van Esch, Nat. Commun., 2017, 8, 15317.

12 Z. Yang, H. Gu, D. Fu, P. Gao, J. K. Lam and B. Xu, Adv. Mater., 2004, 16, $1440-1444$.

13 R. J. Williams, A. M. Smith, R. Collins, N. Hodson, A. K. Das and R. V. Ulijn, Nat. Nanotechnol., 2008, 4, 19-24.

14 (a) J. R. Fores, M. L. M. Mendez, X. Y. Mao, D. Wagner, M. Schmutz, M. Rabineau, P. Lavalle, P. Schaaf, F. Boulmedais and L. Jierry, Angew. Chem., Int. Ed., 2017, 56, 15984-15988; (b) C. Vigier-Carrière, T. Garnier, D. Wagner, P. Lavalle, M. Rabineau, J. Hemmerlé, B. Senger, P. Schaaf, F. Boulmedais and L. Jierry, Angew. Chem., Int. Ed., 2015, 54, 10198-10201; (c) J. Gao, H. M. Wang, L. Wang, J. Y. Wang, D. L. Kong and Z. M. Yang, J. Am. Chem. Soc., 2009, 131, 11286-11287; (d) W. Wang, J. Qian, A. Tang, L. An, K. Zhong and G. Liang, Anal. Chem., 2014, 86, 5955-5961; (e) R. J. Williams, J. Gardiner, A. B. Sorensen, S. Marchesan, R. J. Mulder, K. M. McLean and P. G. Hartley, Aust. J. Chem., 2013, 66, 572-578; $(f)$ S. C. Bremmer, J. Chen, A. J. McNeil and M. B. Soellner, Chem. Commun., 2012, 48, 5482-5484; $(g)$ X. Qin, W. Xie, S. Tian, J. Cai, H. Yuan, Z. Yu, G. L. Butterfoss, A. C. Khuong and R. A. Gross, Chem. Commun., 2013, 49, 4839-4841; (h) L. Chrnopoulou, S. Lorenzoni, G. Masci, M. Dentini, A. R. Togna, G. Togna, F. Bondi and C. Palocci, Soft Matter, 2010, 6, 2525-2532; (i) Y. Liu, V. Javvaji, S. R. Raghavan, W. E. Bentley and G. F. Payne, J. Agric. Food Chem., 2012, 60, 8963-8967; (j) S. Sakai, K. Komatani and M. Taya, RSC Adv., 2012, 2, 1502-1507.

15 J. Yu, X. Xu, F. Yao, Z. Luo, L. Jin, B. Xie, S. Shi, H. Ma, X. Li and H. Chen, Int. J. Pharm., 2014, 470, 151-157.

16 N. Yamada, K. Ariga, M. Naito, K. Matsubara and E. Koyama, J. Am. Chem. Soc., 1998, 120, 12192-12199.

17 A. M. Smith, R. J. Williams, C. Tang, P. Coppo, R. F. Collins, M. L. Turner, A. Saiani and R. V. Ulijn, Adv. Mater., 2008, 20, $37-41$.

18 M. A. Meyers and K. K. Chawla, Mechanical Behavior of Materials, Prentice Hall, Englewood Cliffs, NJ, 1998; J. M. Anderson, A. Andukuri, D. J. Lim and H.-W. Jun, ACS Nano, 2009, 3, 3447-3454. 